\title{
Über höhlenbewohnende Moose
}

\author{
Von LÁSZLó VAJDA ${ }^{1}$ ) \\ Mit 1 Abbildung im Text
}

Die Lichtmenge, die die Moose im allgemeinen beanspruchen, ist viel kleiner, als die der höheren Pflanzen. Viele Moose leben in den Öffnungen der Höhlen, in dunklen Felsritzen und Engpässen, oder am Fuße hoher Felsenwände, an Stellen, deren Lichtverhältnisse keine höheren Pflanzen befriedigen könnten. Manche Moose gehen noch weiter und können sich in solchen Höhlen ansiedeln, in die keine Spur von Außenlicht eindringen kann. Das natürliche Licht wird dort nur durch das elektrische Licht ersetzt, das bei den Besuchen der Höhlen eingeschaltet wird. Die Moose siedeln sich im Umkreis der lichtspendenden Glühbirnen an. Ihr zweites wichtigstes Bedürfnis: die Feuchtigkeit, wird durch die immer feuchte Luft und durch die meist feuchten Wände der Höhlen befriedigt.

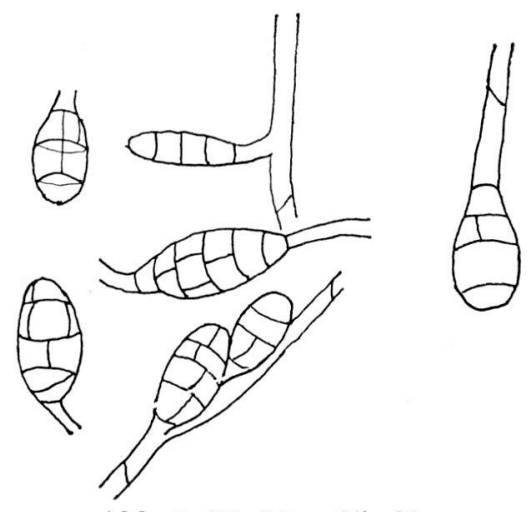

Abb. 1. $80-90 \mu \times 35-40 \mu$

Über die Moosforschungen der ungarischen Kalksteinhöhlen hat schon Dr. A. Boros (1964) in einem Artikel berichtet. Fräulein Dr. K. Verseghy (1965) hat im vorigen Jahre die in der Umgebung von Lillafüred im Bükkgebirge befindlichen zwei Höhlen, die Istvánhöhle und

1) Botanische Abteilung des Ungarischen Naturhistorischen Museums, Budapest, Ungarn. 
die Quellenhöhle, durchsucht und mir die gefundenen Moose zur Aufarbeitung übergeben.

Die Verhältnisse in den Höhlen haben an den Moosen keine besonderen Veränderungen hervorgerufen. Jedenfalls haben die untersuchten Moose keine Geschlechtsorgane hervorgebracht.

In der Quellenhöhle lebt unter anderem Eucladium verticillatum an mehreren Stellen. In seinem Rhizoidengeflecht habe ich besondere Bulbillen beobachtet. Diese sind mehrzellig und erscheinen teils einzeln, teils zu zweit an den Enden der Fäden oder an kurzen Verzweigungen. (Abb. 1). Es sind höchstwahrscheinlich Vermehrungsorgane, Brutkörper. In der Literatur habe ich über solche bei Eucladium keine Erwähnung gefunden.

Die gesammelten Moose, die in beiden Höhlen leben, sind die folgenden:

Pellia fabbroniana Raddi

Eucladium serticillatum/L./Br. eur.

Bryoerythrophyllum recuroirostrum/Hedw./Chen

Tortula muralis/L./Hedw. var. aestiva Brid.

Gymnostomum rupestre Schleich. var. ramosissima Br. eur.

Funaria hygrometrica/L. /Sibth.

Pohlia sp.

Bryum capillare L.

Bryum caespititium L.

Amblystegium serpens/L./Br. eur.

Eurhynchium swartzii/Turn./Hobkirk

Rhynchostegium murale/Neck./Br. eur.

\section{ZUSAMMENFASSUNG}

Unter den Moosarten, welche von Dr. K. Verseghy in den Höhlen von Lillafüred gesammelt wurden, wurde Eucladium verticillatum (L.) Br. Eur. gefunden, das merkwürdige Bulbillae aufwies, die aus zwischen zwei und vielen Zellen am Ende der Fädchen zusammengesetzt waren. Es ist möglich, daß diese spezielle reproduktive Organe darstellen, welche bis jetzt bei diesem Genus nicht bekannt waren. Keines der Moose, die in den Höhlen leben, entwickelte Geschlechtsorgane.

\section{SUMMARY}

Among the mosses collected by Dr. K. Verseghy in the caves of the environment of Lillafured Eucladium serticillatum (L.) Br. Eur. was found which had some peculiar bulbillae composed of two to many cells on the ends of the filaments. They may represent special reproductive organs as yet unknown in this genus. None of the mosses living in the caves developed sex organs. 


\section{LITERATUR}

Boros, A. (1964) - Über die Moose, die unter dem Einfluß der elektrischen Beleuchtung in das Innere der Höhlen in Ungarn und in der Tschechoslowakei eindringen. Internatl. J. Speleol. I/1-2: 45-46.

Verseghy, K. (1965) - Die Pflanzenwelt der Höhlen bei Lillafüred. Internatl. J. Speleol. I/4: 553-560. 